\title{
ESTUDIO PRELIMINAR DE LA ALIMENTACION DE LAS LARVAS DE Cancer antennarius (CRUSTACEA, BRACHIURA) EN CONDICIONES CONTROLADAS
}

\author{
por \\ A Denise Re A. \\ $y$ \\ L. Fernando Bückle R.* \\ Centro de Investigación Científica y Educación Superior \\ de Ensenada, Baja California ( CICESE ) \\ Apdo. postal 2732, Ensenada. B.C.. México.
}

\section{RESUMEN}

Cultivos de larvas de Cancer antennarius fueron alimentados con yema de huevo, Skeletonema costatum, Protein 96, alimento para gato comercial (Cat Chow), y sus combinaciones, en concentraciones de 0.007 ó $0.001 \mathrm{mg} / 1$. También se ensayó suministrando Branchionus plicatilis en densidades progresivas. En ésta investigación se alcanzó el estadío Zoea III con una sobrevivencia de un $0.38 \%$ al dieciochoavo día. Se diseñó un sistema experimental especial para controlar la densidad del alimento y el cambio continuo de agua de los acuarios.

\section{ABSTRACT}

Larvas culture of Cancer antennarius were fed with egg yolk, Skeletonema costatum, Protein 96 and commercial cat food (Cat Chow). These food items were provided single or combined in concentrations of 0.001 or $0.007 \mathrm{mg} / 1$. Bracbionus plicatilis, provided in progressive higher densities, was also tested. In this work, Zoea III was attained with a survivorship of $0.38 \%$ at the eighteenth day. A special experimental system was design to control food densities and continous water exchange in the aquaria.

\section{INTRODUCTION}

El litoral del Pacífico y Golfo de California en las zonas correspondientes a los estados de Baja California y Baja California Sur de México, se han distinguido por su gran variedad de especímenes marinos de alto valor nutritivo, entre los cuales se encuentra Cancer antennarius que ha sido explotado en cantidades relativamente bajas.

Durante los años 1971 y 1975 la recolección de tenazas de C. antennarius en Baja California Norte fue superior a los tres años intermedios. A partir del últi- 
mo, hubo un aumento gradual de las pesquerías, alcanzando en 1978 una producción de un $70 \%$ más alta de la observada en 1976. Así en ocho años estadísticos, el promedio extraído fue de 29.5 toneladas por año (Fig. 1) (com. pers. Departamento de Pesca del Estado, Ensenada, B.C.).

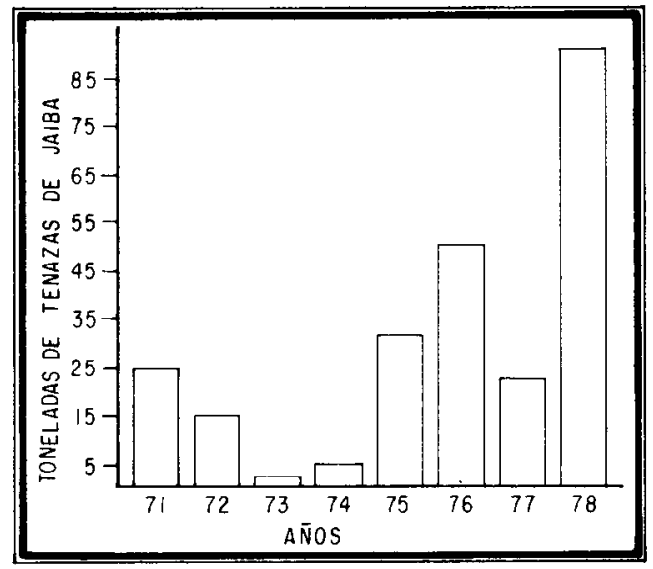

Fig. 1. Producción anual de tenazas de jaiba en el Municipio de Ensenada, Baja California.

Fig. 2. Distribución geográfica de Cancer antennarius modificado de Kathbun (1939). Las zonas achuradas en E.E.U.U. son Bahía Tomales, Bahía San Francisco, Bahía de Half Moon, Santa Cruz, Bahía de Monterrey, Santa Bárbara, Bahia de Santa Mónica, Bahía de San Pedro, Long Beach, Laguna Beach, Isla Santa Catalina, La Jolla y San Diego. En México: Bahía de Todos Santos, Isla de Todos Santos y Punta Abreojos.

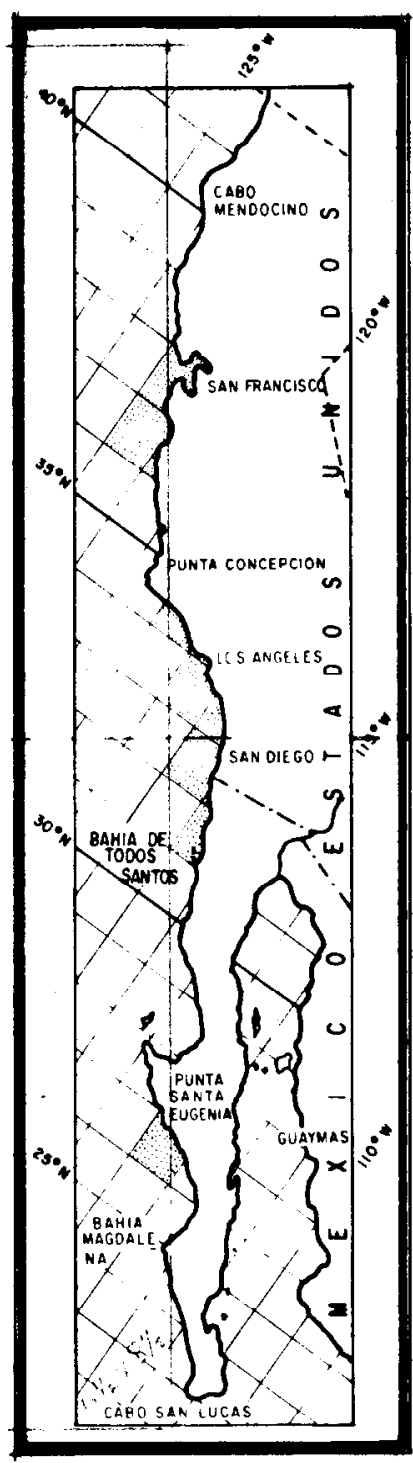


C. antennarius vive en sustratos arenosos, rocosos y lodosos (Fig. 2), tiene diferentes nombres vernaculares dependiendo del lugar de origen, por ejemplo, "cangrejos de roca" o "jaiba" como se le denomina en Baja California Norte (México).

Las observaciones de campo y laboratorio indican que el desove y la maduración de los huevos de esta especie, ocurre principalmente entre abril y septiembre. En los otros meses, las hembras maduras son más bien escasas y se localizan en lugares hondos cerca de la costa, sin embargo, en la Bahía de Todos Santos (Lat. $31^{\circ} 40^{\prime} \mathrm{N}$, Long. $116^{\circ} 36^{\prime} \mathrm{W}$ ) es posible encontrar jaibas ovígeras todo el año.

Las hembras fertilizadas desovan después de seis o siete meses, hecho directamente comprobado en el laboratorio. Los huevos son adheridos a los pleopodos, donde con los pereiópodos se realiza un cuidado meticuloso para permitir una adecuada aireación y protección durante el desarrollo embriológico. Los huevos tienen una coloración inicial anaranjado brillante que a medida que se forma la larva cambia a diferentes tonalidades de gris, debido a la reabsorción del deutoplasma.

La Aquacultura para ser rentable requiere de un número inicial apreciable de larvas para obtener una producción masiva de animales metamorfoseados. Hasta el momento sólo se ha llegado en contadas ocasiones en el género Cancer al estadío Megalopa. Anderson y Ford, (1976); Trask, (1970); Sastry, (1977a); Poole, (1966); Mir, (1961); Buchanan y Milleman, (1969); Roesijadi, (1976) y Sastry (1977b) han descrito algunos estadíos de desarrollo de las larvas de Cancer spp.

También se ha estudiado el crecimiento de las larvas de Cancer magister (Reed, 1969) y de C.antbonyi (Anderson y Ford, 1976), como los adultos de $C$. pagurus (Bennet, 1973) y de C. magister y C. pagurus entre otros (Hartnoll, 1974). Además se ha investigado el consumo de oxígeno de las larvas de $C$. productus y Panulirus interruptus por Belman y Childress en 1973. Las investigaciones relativas a este género son muchas, pero en particular en relación a $C$. antennarius y específicamente en los problemas de alimentación de los estadíos larvales, no ha sido estudiado sistemáticamente y constituye un aspecto fundamental de la depuración de una técnica Aquacultural.

La Artemia salina (Anderon y Ford, 1976; Poole, 1966; Trask, 1970; Sastry, 1977a) fue utilizada como alimento principal en el cultivo de larvas de Cancer magister, C. antennarius, $C$. anthonyi y $C$. irroratus. También se han usado otros alimentos menos comunes como huevos de Arbacia sp (Mir, 1961); el primer estadío nauplio de Balanus tintininnabulum y B. amphitrite; Tetramin (alimento para alevines) mejillón molido Mytilus spp. (Reed, 1969) e hígado de res (Mir, 1961). Además se han llevado a cabo experiencias de nutrición con 
Skeletonema costatum y Thallasiosira pseudonana a una densidad de 25,000 $\mathrm{cel} / \mathrm{ml}$ (Fisher y Nelson, 1977).

Con todos estos antecedentes se planteó buscar alimentos más adecuados para cultivar las larvas de Cancer antennarius y tratar de optimizar el cultivo desde la larva Zoea I hasta Megalopa, con la consideración de aumentar la materia orgánica presente en el agua de mar $(0.005 \mathrm{mg} / 1$ (Jorgensen, 1954).

En México hasta el momento no se ha encontrado ninguna información en relación al cultivo de larvas o de adultos de esta especie. En este trabajo se describen las primeras experiencias mexicanas de cultivo de larvas de C. antennarius.

\section{MATERIALES Y METODOS}

Debido a la importancia que tiene el estado fisiológico de los huevos para la realización de experimentos dirigidos al cultivo de larvas, se tomaron medidas preventivas consistentes en efectuar la recolección de los machos y las hembras ovígeras al amanecer, controlar las condiciones básicas y evitar el stress por manipulación mecánica. Para ésto se dispuso de un termómetro, un oxigenómetro y hieleras que contenían bolsas con agua de mar congelada. En las hieleras se controlaban las condiciones de oxígeno disuelto y temperatura durante el traslado de los animales al laboratorio, ubicado aproximadamente a cuatro kilómetros del lugar de pesca.

Las hembras seleccionadas para los experimentos fueron aquellas cuyos huevos tenían una coloración anaranjado brillante, La aclimatación de los animales y las condiciones de laboratorio, se hizo incrementando la temperatura del agua gradualmente y a intervalos regulares ( 1 grado $\mathrm{C}$ cada dos horas).

Para hacer observaciones etológicas, algunas hembras y machos fueron retenidos en cautiverio, en un filtro biológico en sustrato arenoso $\mathrm{v}$ de una canaridad de 8001 aproximadamente. En este acuario fue posible observar la cópula de dos parejas.

El sistema experimental de cultivo fue montado en un estanque de fibra de vidrio de una tonelada de capacidad (Fig. 3-1) que descansa sobre una base de madera (Fig. 3-2). En la parte superior del estanque tiene una estructura reticulada de acrílico de $13 \mathrm{~mm}$ de espesor que deja libre 100 cuadrados de $9 \times 9 \mathrm{~cm}$ (Fig. 3-3); los cuadrados son la estructura de soporte para los acuarios. Cada acuario está constituido por cuatro partes, las dos primeras son un ensamble de dos piezas de material plástico ABS (Fig. 3-4) que sostiene una bolsa de polietileno tubular (Fig. 3-5) de $75 \mathrm{~cm}$ de largo. En el extremo tiene un embudo (Fig. 3-6) sellado con un tapón de goma del número 000 con un orificio en el centro que tiene conectado una manguera de aire (Fig. 3-7) de $0.04 \mathrm{~mm}$ de diámetro. A trece centrímetros del borde superior del embudo se instaló un sistema para sostener 


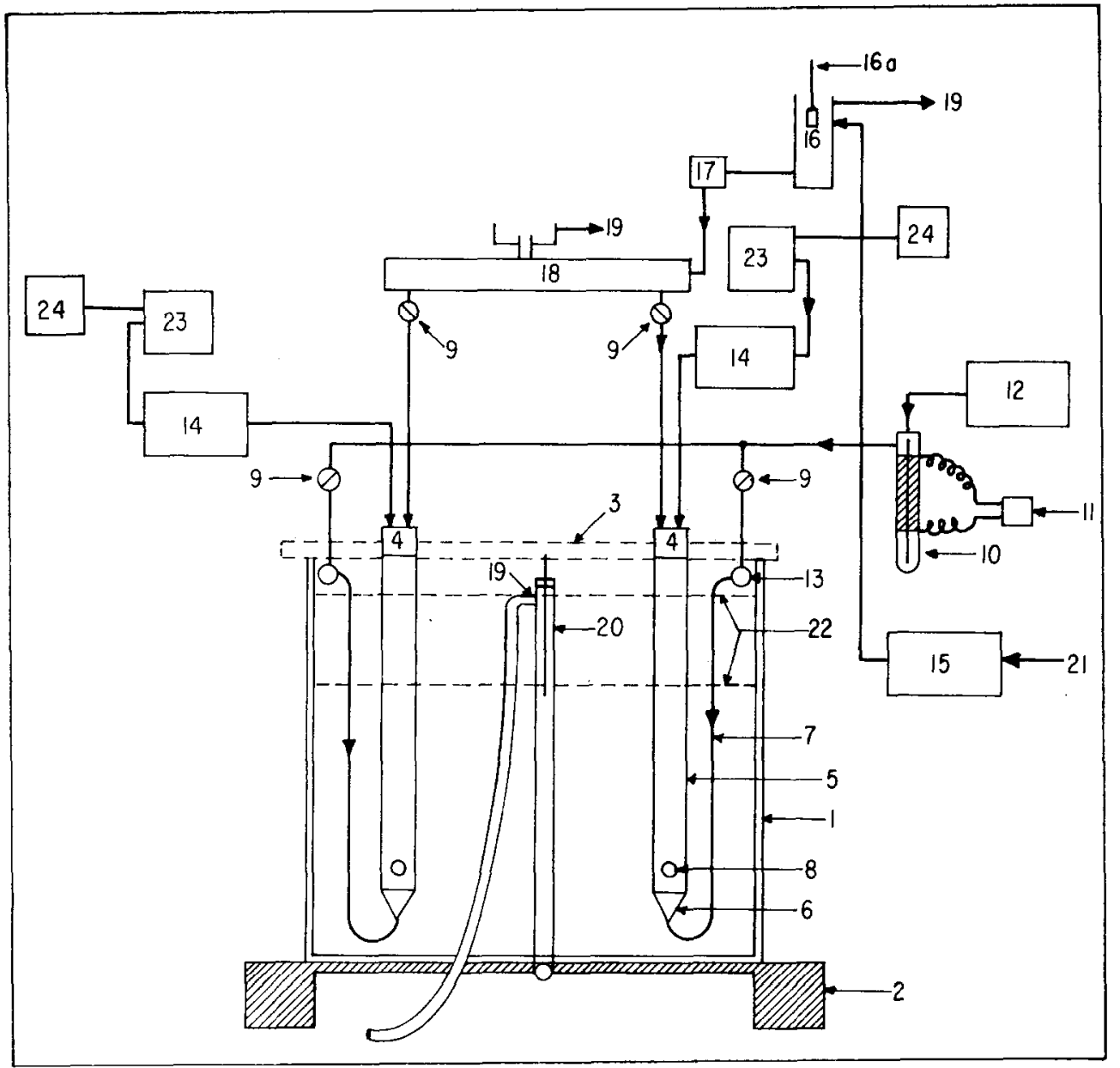

Fig. 3.1. Estanque de fibra de vidrio de 1 Ton; 2.- Base de madera, 3.- Estructura de acrílico; 4.- Anillo de soporte ABS; 5.- Bolsa de polietileno; 6 .- Embudo; 7.- Manguera de aire; 8.- Malla, 9.- Llaves de paso; 10.- Filtro de aire seco; 11.- Transformador; 12.- Bomba de aire; 13.- Distribuidor de aire seco; 14.- Bombas paristál ticas; 15.- Motobomba; 16.Torre de acrílico; 16a.- Aireador; 17.- Filtro de algodón plástico; 18.- Cámara de distribución; 19.- Rebalse; 20.- Control de niveles; 21 .- Suministro de agua; 22.- Niveles de agua; 23.- Cajas alimentadoras; 24.- Motor.

una malla de 100 micras cuya función es permitir la salida del agua de recambio (Fig. 3-8). Los acuarios tienen una capacidad de cuatro litros que pueden ser regulados al volumen que se requiera. Ocupan un espacio mínimo por lo que es posible instalar sobre el soporte de acrílico 96 acuarios, lo que redunda en una gran amplitud de posibilidades experimentales.

El suministro de agua (Fig. 3-21) al sistema fué impulsado por una motobomba de una capacidad máxima de $1800 \mathrm{ml} / \mathrm{min}$ (Ministaltic-Manostat) (Fig. 3-15) que lleva el agua de mar a la parte superior del sistema a una torre de acrílico transparente (Fig. 3-16) que tiene un rebalse (Fig. 3-19) en la salida un fil- 
tro (Fig. 3-17). El agua se transfiere a una cámara de distribución (Fig. 3-18) que mantiene una capacidad constante de agua con el rebalse (Fig. 3-19) para unifomar el fluido de 80 mangueras, 40 en cada lado del sistema. El agua baja a cada uno de los acuarios por una red de tuberías que recorren todo el sistema. De esta manera el goteo constante $(8 \mathrm{ml} / \mathrm{min})$ incrementa el nivel de agua en cada acuario y en conjunto elevan el del estanque (Fig. 3-22).

Fuera del estanque se instaló un sistema de control de niveles, (Fig. 3-20) regulado por un mecanismo de sifón, que se acciona cuando la altura del agua sube a un punto prefijado. Este sistema ofrece las ventajas de mantener una limpieza constante del acuario, eliminando los catabolitos y el alimento que no fue ingerido por los animales cultivados.

El aire se inyectó con una bomba "Conde" (Fig. 3.12) en cuyo recorrido se secó y filtró en una unidad de vidrio (Fig. 3-10) rodeada de una resistencia eléctrica conectada a un transformador de 20 Watts (Fig. 3-11). La resistencia mantiene la unidad caliente y el aire que circula se seca y se filtra con carbón activado antes de entrar al sistema de acuarios. El objetivo de esta unidad es evitar que el sistema se humedezca y se contamine con protozoos. El aire filtrado pasa por una válvula de regulación general (Fig. 3-9) a un distribuidor (Fig. 3-13) que lo reparte uniformemente a cada uno de los acuarios (Fig. 3-7).

Para dosificar el alimento de las larvas, se instalaron ocho cajas de acrílico de cuatro litros de capacidad cada una (Fig. 3-23). Cada caja tiene una paleta de acrílico movida por un mecanismo de poleas y accionado por un motor de $1 / 100$ HP de 32 RPM (Fig. 3-24). De las cajas salen cinco mangueras conectadas a las bombas peristálticas (Fig. 3-14) de veinte canales cada una (Manostat Modelo Standard de 115 Voltios). Los alimentos impulsados por las bombas peristálticas se dirigieron a través de mangueras ( $1 / 16$ de pulgada) a cada acuario y su reparto se hizo al azar.

Cada alimento fue representado por una letra mayúscula; A, B, C, en el primer experimento y $\mathrm{A}^{\prime}, \mathrm{B}^{\prime}, \mathrm{C}^{\prime}$ en el segundo. Las concentraciones de alimentos ensayadas de $100 \%, 50 \%, 33 \%, 0 \%$ y sus réplicas se indican en la Tabla 1.

El procedimiento experimental se inició después de la fase de aclimatación de los animales y de la maduración de los huevos, para lo cual las hembras fueron transferidas a estanques de eclosión con un volumen (200 1) prefijado de agua de mar filtrada a 30 micras. Al empezar la eclosión de las larvas se mantuvo una aireación moderada para impedir que estas fueran arrastradas y se aglutinaran en el fondo del estanque. Cuando todas las larvas habían eclosionado, las hembras fueron transvasadas para facilitar el manejo del cultivo y poder extraer del fondo del estanque todas las excretas depositadas por las progenitoras y evitar en lo posible la proliferación de bacterias. 
Tabla 1. Distribución de la concentración $(\%)$ de los alimentos. Los tratamientos se indican en la columna de la izquierda. A,B,C, alimentos; "I" testigos.

\begin{tabular}{|c|c|c|c|c|}
\hline & \multicolumn{3}{|c|}{ ALIMENTOS $(\%)$} & \multirow{2}{*}{$\begin{array}{c}\text { REPLICAS } \\
\text { EXPERIMENTALES } \\
\text { POR TRATAMIENTO }\end{array}$} \\
\hline & A & B & C & \\
\hline A & 100 & - & - & 5 \\
\hline B & - & 100 & - & 5 \\
\hline $\mathrm{C}$ & - & - & 100 & 5 \\
\hline$A B$ & 50 & 50 & - & 5 \\
\hline$B C$ & - & 50 & 50 & 5 \\
\hline$A C$ & 50 & - & 50 & 5 \\
\hline$A B C$ & 33 & 33 & 33 & 5 \\
\hline "1" & 0 & 0 & 0 & 5 \\
\hline
\end{tabular}

La eclosión de las larvas demoró aproximadamente 24 hs y por lo general se iniciaba al atardecer o en la noche. Las larvas recien eclosionadas mudan de Pre Zoea a Zoea I en los primeros 15 minutos (Mir, 1961; Buchanan y Milleman, 1969).

Para conocer el número de larvas del cultivo, el contenido del estanque de eclosión se uniformó. Las muestras (cinco alicuotas) se colectaron con una botella de Van Dorn modificada a un volumen de $36 \mathrm{ml}$ (Bückle et al. 1976) El volumen del muestreador se calculó (Cochran, 1978) con el conocimiento previo del número inicial de larvas que se iban a cultivar y a la capacidad de agua de los acuarios de experimentación. Una vez estimada la densidad promedio de larvas en el estanque de eclosión se procedió a calcular una alicuota, que transferida a los acuarios de experimentación (Fig. 3-5) diera la concentración deseada.

La preparación de los alimentos se hicieron con diferentes substancias, pesadas en una balanza Sartorius Modelo 1204 MP y molidas manualmente en un mortero de porcelana. Seguidamente eran disueltos en agua de mar esterilizada en un sistema ultravioleta, en una cantidad suficiente, como para llenar los acuarios del sistema de alimentación (4 1 cada uno). Como el fluido del sistema de agua proporcionaba $8 \mathrm{ml} / \mathrm{min},(4141 /$ día en 40 acuarios de experimentación) fue necesario aumentar la concentración de los alimentos de $0.001 \mathrm{gr} / 1$ a $0.116 \mathrm{gr} / \mathrm{l}$, para contrarestar los efectos de dilución. Los alimentos utilizados en los experimentos se indican en la Tabla 2 y la composición química de ellos en la Tabla 3 . Los experimentos se condujeron a una salinidad de 32 o/o. 
Tabla 2. Combinación de alimentos proporcionados al primero (I) y al segundo (II) experimento. Vit. C.- Vitamina C; Al./gato.- Alimento para gato (Cat Chow); SkeletonemaSkeletonema costatum; "I".- Testigo.

\begin{tabular}{|c|c|c|c|c|c|c|c|}
\hline \multicolumn{4}{|c|}{ TRATAMIENTOS } & \multicolumn{4}{|c|}{ EXPERIMENTO } \\
\hline$A$ & $B$ & $c$ & $A B C$ & $A B$ & $B C$ & $C A$ & 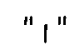 \\
\hline $\begin{array}{l}\text { Yemo } \\
\text { Vit. C }\end{array}$ & $\begin{array}{l}\text { Al./Gato } \\
\text { Vit. C }\end{array}$ & $\begin{array}{l}\text { Skele tonemo } \\
\text { Vitomina C }\end{array}$ & $\begin{array}{c}\text { Yemo } \\
\text { Al. / Gato } \\
\text { Skeletonema } \\
\text { Vitomina C }\end{array}$ & $\begin{array}{c}\text { Yemo } \\
\text { Al./Gato } \\
\text { Vitamino C }\end{array}$ & $\begin{array}{c}\text { Al./ Goto } \\
\text { Skele tonema } \\
\text { Vitom in a C }\end{array}$ & $\begin{array}{l}\text { Skeletonemo } \\
\text { Yema } \\
\text { Vitamina C }\end{array}$ & Vit. $C$ \\
\hline
\end{tabular}

\begin{tabular}{|c|c|c|c|c|c|c|c|}
\hline \multicolumn{4}{|c|}{ TRATAMIENTOS } & EXPERIMENTO & \multicolumn{3}{|l|}{ II } \\
\hline$A^{\prime}$ & $B^{\prime}$ & $c^{\prime}$ & $A B C^{\prime}$ & $A B^{\prime}$ & $B C^{\prime}$ & $C A^{\prime}$ & "।," \\
\hline $\begin{array}{c}\text { Ye ma } \\
\text { de huevo } \\
\text { Colesterol }\end{array}$ & $\begin{array}{l}\text { Brachionus } \\
\text { plicatillis } \\
\text { Colesterol }\end{array}$ & $\begin{array}{l}\text { Protein } 96 \\
\text { Colesterol }\end{array}$ & $\begin{array}{l}\text { Yemo huevo } \\
\text { Brochionus } \\
\text { plicatillis } \\
\text { Prote in } 96 \\
\text { Colesterol }\end{array}$ & $\begin{array}{l}\text { Yema huevo } \\
\text { Brachionus } \\
\text { plicatillis } \\
\text { Colesterol }\end{array}$ & $\begin{array}{c}\text { Brochionus } \\
\text { plicotillis } \\
\text { Colesterol } \\
\text { Protein } 96\end{array}$ & $\begin{array}{l}\text { Protein } 96 \\
\text { Yema } \\
\text { Colesterol }\end{array}$ & $\begin{array}{l}\text { Coles- } \\
\text { terol }\end{array}$ \\
\hline
\end{tabular}

En el primer experimento se proporcionó yema de huevo, comida para gato comercial (Cat Chow) y Skeletonema costatum. De los dos primeros se pesaron 7.6 gr y se diluyeron en 9.3331 de agua de mar filtrada y esterilizada con rayos ultravioletas para mantener dentro de los acuarios una concentración de 0.007 gr/l. A todos los tratamientos se les añadió ácido ascórbico en una proporción de $0.25 \%$ del peso del alimento seco. La administración del alimento se hizo con una velocidad de goteo de $1 \mathrm{ml} / \mathrm{min}$, durante 48 horas. Al cabo de este lapso, el alimento se preparaba de nuevo y de tal forma que no hubiera una interrupción de más de media hora.

Los alimentos ensayados en el segundo experimento fueron yema de huevo, Protein 96 y el Rotífero Bracbionus plicatilis cultivados según las indicaciones de Theilacker y McMaster, (1971). Los Rotíferos fueron administrados al ensayo en densidades progresivas. La concentración de yema de huevo y Protein 96 proporcionada a las larvas fue de $0.001 \mathrm{gr} / \mathrm{l}$.

Cada segundo día se tomaron dos muestras por acuario experimental; las larvas se transferían a cajas de Petri reticuladas, donde se determinaba el porcentaje de sobrevivencia. Las muestras fueron fijadas con una gota de la solución histológica de Bouin por 24 horas, luego fueron lavadas con etanol al $70 \%$ o hasta que el color del fijador era eliminado. 
Denise Re-Buckle

Tabla 3. Composición química de los alimentos probados experimentalmente.

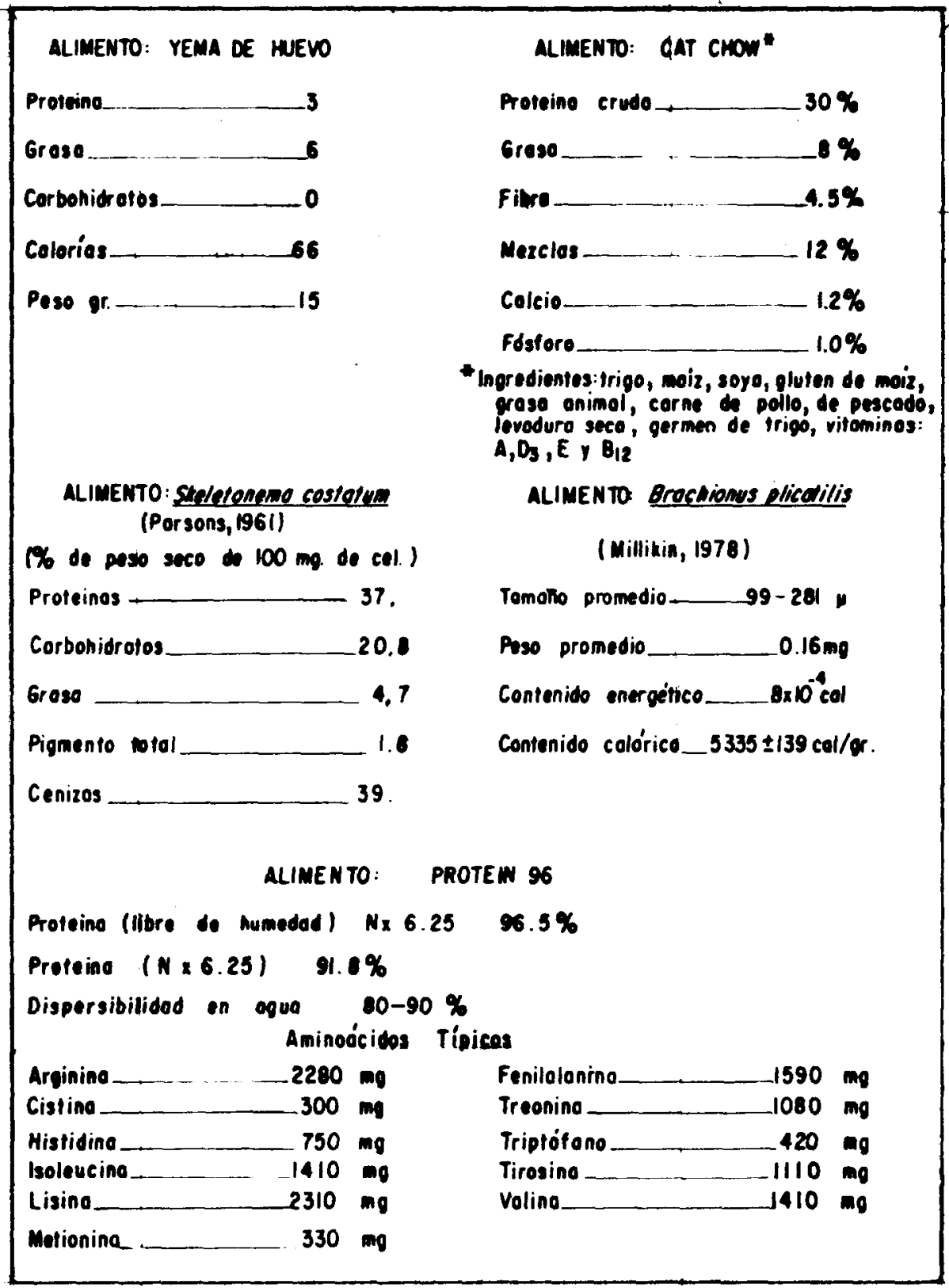


Con los resultados de la sobrevivencia larval ( $\% / 0$ ) versus tiempo, se hizo una gráfica por cada uno de los tratamientos alimenticios con el fin de calcular primero las pendientes $(\mathrm{m})$ por pares de datos y obtener una pendiente promedio $(\bar{m})$ de cada tratamiento. Para el examen de la información se utilizaron los estadígrafos Análisis de Varianza (ANVA) general, "A Priori" y "A Posteriori" (Sokal y Rholf, 1969), (Schefler, 1969).

\section{RESULTADOS}

Se hicieron seis ensayos, de los cuales se reportan los dos mas relevantes y se describen como experimento I y II. En cuatro ensayos que no se informan (resultados no significativos), los alimentos que se probaron fueron almeja molida Tivela stultorum, levadura, una mezcla de harina de maiz, de trigo y de soya y un macerado de huevos de la jaiba $C$. antennarius.

\section{EXPERIMENTO I}

A una hembra ovigera colectada en la Bahía de Todos Santos, adaptada a las condiciones imperantes en el laboratorio le eclosionaron las larvas un 29 de julio. Al día siguiente se agregaron a cada uno de los acuarios $(=40)$ de experimentación 10200 larvas en el estadío de Zoea I ( 3 larvas/ml). El cultivo se hizo a $23.0^{\circ} \mathrm{C}$., con una concentración de oxígeno de $6.7 \mathrm{ppm}$.

Los alimentos proporcionados en este experimento fueron yema de huevo, comida para gato comercial y Skeletonema costatum en una densidad 200000 cels/ml (Tabla 2).

En este experimento no se tuvieron evidencias de muda. El sexto día fue crítico y las poblaciones de larvas murieron.

En la Tabla 4 se muestran los resultados de sobrevivencia en los controles hechos en el tercero y quinto día de experimentación.

El logaritmo de las pendientes de sobrevivencia promedio ( $\mathrm{Ln} \mathrm{m}$ ) de las larvas se graficaron contra el tiempo (Fig. 4) de la cual se obtuvieron las pendientes $m$ de cada tratamiento como un índice de la sobrevivencia larval en el tiempo ( $\mathrm{Ta}$ bla 5). Al comparar los tratamientos con la sobrevivencia (m) de las larvas por un Análisis de Varianza (Tabla 6) se estableció que al $0.05 \%$ o no se detectaba una diferencia significativa en los resultados obtenidos $[F=0.05(7,14)=2.76$; Fs $=$ 1.9795]. Siendo F mayor que Fs no se rechazó Ho (Rohlf y Sokal, 1969). Aún teniendo el resultado de ANVA no significativo, se aplicó el estadígrafo "A Priori" de comparación de medias (Snedecor y Cochran, 1978) para someter el experimento a un análisis más delicado. El estadígrafo indicó que el experimento tenía una diferencia significativa al quinto dia, especialmente en la combinación del alimento yema de huevo y $S$. costatum (CA) con respecto a todos los demás tratamientos (Tabla 7). 


\section{Denise Re-Buckle}

Tabla 4. Sobrevivencia de las larvas $C$. antennarius del primer experimento, controlado al tercero y al quinto día.

\begin{tabular}{|c|c|c|c|c|c|c|c|}
\hline & \multicolumn{4}{|c|}{ REPLICAS } & & \multirow{2}{*}{ Tiempo(dios) } & \multirow{2}{*}{$\begin{array}{l}\text { Sobrevivencio } \\
\text { lotol } R\end{array}$} \\
\hline Alimento & $r 1$ & 12 & 13 & 14 & 15 & & \\
\hline A & 52 & 125 & 17 & 56 & 57 & 3 & $59.69 \%$ \\
\hline B & 66 & 35 & 27 & 43 & 25 & 3 & $38.11 \%$ \\
\hline$c$ & 71 & 36 & 55 & 82 & 46 & 3 & 56.38 \\
\hline $\begin{array}{c}A B C \\
A B\end{array}$ & $\begin{array}{l}55 \\
32\end{array}$ & $\begin{array}{l}38 \\
19\end{array}$ & $\begin{array}{l}23 \\
17\end{array}$ & $\begin{array}{l}20 \\
43\end{array}$ & $\begin{array}{l}35 \\
17\end{array}$ & $\begin{array}{l}3 \\
3\end{array}$ & $\begin{array}{l}33.25 \\
26.97\end{array}$ \\
\hline \multirow{2}{*}{$\begin{array}{ll}8 & C \\
C & A \\
& 1\end{array}$} & $\begin{array}{l}76 \\
72\end{array}$ & $\begin{array}{l}19 \\
81\end{array}$ & $\begin{array}{l}48 \\
45\end{array}$ & $\begin{array}{l}18 \\
33\end{array}$ & $\begin{array}{l}19 \\
30\end{array}$ & $\begin{array}{l}3 \\
3\end{array}$ & $\begin{array}{ll}39.13 & \% \\
56.14 & \%\end{array}$ \\
\hline & 54 & 79 & 70 & 32 & 28 & 3 & 57.11 \\
\hline$A$ & 2 & $i$ & 0 & 0 & 13 & 5 & 3.11 \\
\hline $\mathbf{B}$ & 1 & 0 & 3 & 2 & 1 & 5 & 1.70 \\
\hline C & 1 & 0 & 0 & 0 & 0 & 5 & 0.19 \\
\hline$A B C$ & 11 & 2 & 2 & 8 & 1 & 5 & 4.60 \\
\hline A B & 18 & 4 & 21 & 4 & 4 & 5 & 7.60 \\
\hline$\theta \epsilon$ & $\theta$ & 1 & $\theta$ & $\theta$ & $\theta$ & 5 & 0.24 \\
\hline$C_{1} A$ & $\begin{array}{r}15 \\
1 \\
\end{array}$ & $\begin{array}{c}40 \\
1 \\
\end{array}$ & $\begin{array}{r}15 \\
0 \\
\end{array}$ & $\begin{array}{l}9 \\
0 \\
\end{array}$ & $\begin{array}{l}5 \\
0 \\
\end{array}$ & $\begin{array}{l}5 \\
5 \\
\end{array}$ & $\begin{array}{r}19.20 \% \\
0.48 \% \\
\end{array}$ \\
\hline
\end{tabular}

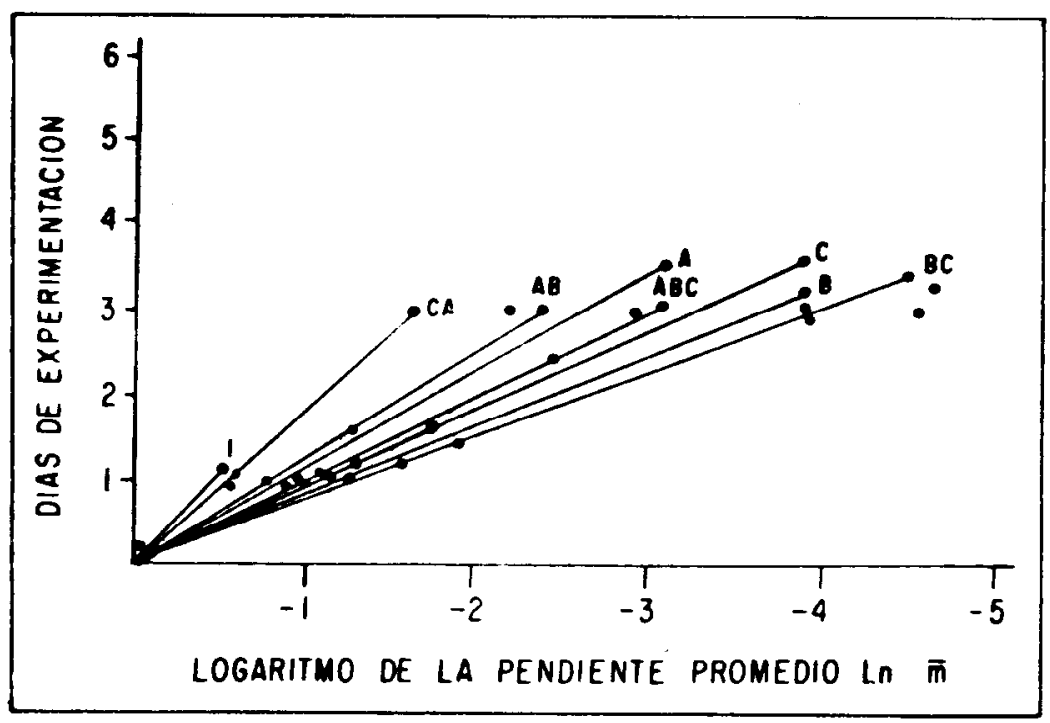

Fig. 4.- Contrastación de las pendientes promedio de sobrevivencia para cada combinación alimenticia del experimento I versus tiempo. 


\section{ALIMENTACION DE LARVAS}

Tabla 5. Valores de las pendientes $(\mathrm{m})$ y sus promedios $(\mathrm{m})$ de cada tratamiento del experimento I calculados en base a los datos de sobrevivencia en el tiempo.

\begin{tabular}{|c|cccccccc|}
\hline ALIMENTO & $A$ & $B$ & $C$ & $A B C$ & $A B$ & $B C$ & $C A$ & "1" \\
\hline m(pendientes) & 0.54 & 0.94 & 0.56 & 1.10 & 1.30 & 0.99 & 0.56 & 0.54 \\
& 0.99 & 1.30 & 1.30 & 1.03 & 0.73 & 1.53 & 0.55 & \\
& 1.24 & 1.49 & 1.67 & 1.00 & 0.45 & 1.80 & 0.55 & \\
\hline$n$ & 3 & 3 & 3 & 3 & 3 & 3 & 3 & 1 \\
\hline $\bar{m}$ (promedio) & 0.91 & 1.24 & 1.18 & 1.04 & 0.83 & 1.44 & 0.55 & 0.54 \\
\hline$S^{2}$ & 0.138 & 0.076 & 0.319 & 0.002 & 0.188 & 0.170 & 0.00003 & \\
\hline
\end{tabular}

Tabla 6. Análisis de Varianza de comparación de las pendientes promedio de sobrevivencia de todos los tratamientos alimenticios del experimento I.

\begin{tabular}{|l|c|c|c|c|}
\cline { 2 - 5 } \multicolumn{1}{c|}{} & \multicolumn{4}{c|}{ ANALISIS "ANVA" EXPERIMENTO I } \\
\hline $\begin{array}{l}\text { Fuente de } \\
\text { Varioción }\end{array}$ & $g 1$ & S S & MS & Fs \\
\hline Entre Grupos & 7 & 1.76 & .2514 & 1.9795 \\
\hline Intro Grupos & 14 & 1.7892 & .1278 & \\
\hline Total & 21 & 3.549 & & \\
\hline
\end{tabular}

Tabla 7. Prueba "A Priori" para comparar las pendientes promedio de sobrevivencia larval en cada uno de los tratamientos alimenticios en el experimento $I$.

\begin{tabular}{|l|l|l|l|l|}
\hline $\begin{array}{c}\text { Combinoción de } \\
\text { Alimento }\end{array}$ & $\begin{array}{c}\text { Fs } \\
\text { Pendientes }\end{array}$ & $F($ Teorio $)$ & \multicolumn{1}{|c|}{ MS } & \multicolumn{1}{|c|}{ Volor } \\
\hline B vs todos & 12.222 & $F 0.05(1,14)=4.60$ & .1278 & Significotivo \\
\hline A vs ABC & .0234 & $F 0.05(1,14)=4.60$ & .1278 & No Significolivo \\
\hline A vs AB & .009 & $F 0.05(1,14)=4.60$ & .1278 & No Significotivo \\
\hline Testigo vs Todos & 3.7997 & $F 0.05(1,14)=4.60$ & .1278 & No Significotivo \\
\hline CA vs Todos & 20.564 & $F 0.001(1,14)=17.1$ & .1278 & Aifomente Significofivo \\
\hline AB vs Todos & 16.694 & $F 0.005(1,14)=11.1$ & .1278 & Significafivo \\
\hline$A B$ vs CA & .0970 & $F 0.05(1,14)=4.60$ & .1278 & No Significotivo \\
\hline
\end{tabular}


Tabla 8. Proporción de Brachionus plicatilis versus larvas de C. antennarius que se administró progresivamente al cultivo.

\begin{tabular}{|c|ccccccc|}
\hline \multirow{2}{*}{ FECHA } & \multicolumn{7}{|c|}{ Rofiferos : Lorvas } \\
\cline { 2 - 8 } & $A^{\prime}$ & $B^{\prime}$ & $C^{\prime}$ & $A B C^{\prime}$ & $A^{\prime}$ & $B^{\prime}$ & $C^{\prime}$ \\
\hline 25 de Enero & 0 & $2: 1$ & 0 & $1: 1$ & $1: 1$ & $1: 1$ & 0 \\
\hline 27 de Enero & 0 & $7: 1$ & 0 & $2.5: 1$ & $3.5: 1$ & $3.5: 1$ & 0 \\
\hline 28 de Enero & 0 & $11: 1$ & 0 & $3.6: 1$ & $5.5: 1$ & $5.5: 1$ & 0 \\
\hline 2 de Febrero & 0 & $12: 1$ & 0 & $4: 1$ & $6: 1$ & $6: 1$ & 0 \\
\hline 4 de Febiero & 0 & $20: 1$ & 0 & $7: 1$ & 10.1 & $10: 1$ & 0 \\
\hline
\end{tabular}

\section{EXPERIMENTO II}

Otra hembra que había sido fecundada en el laboratorio el 13 de mayo, desovó el 13 de diciembre. Las larvas eclosionaron 39 días después. El estudio se inició introduciendo 5000 larvas por acuario (1.4 larvas $/ \mathrm{ml}$ ). El experimento se condujo a $17.8^{\circ} \mathrm{C}$ y el oxígeno disuelto fue de $8.7 \mathrm{ppm}$.

En la Tabla 9 se indican los porcentajes de sobrevivencia larval en los controles hechos al cuarto y séptimo día, donde en el último se destaca el tratamiento $B^{\prime}$ con un $5.05 \%$ de sobrevivencia del estadío Zoea I.

Tabla 9. Sobrevivencia de las larvas de C. antennarius del experimento II.

\begin{tabular}{|c|c|c|c|c|c|c|c|c|}
\hline \multirow[b]{2}{*}{ Alimento } & \multicolumn{5}{|c|}{ REPLICAS } & \multirow{2}{*}{\multicolumn{2}{|c|}{ Tiempoldios) }} & \multirow{2}{*}{$\begin{array}{l}\text { Sobrevivencia } \\
\text { total } \overline{\mathrm{X}}\end{array}$} \\
\hline & rI & $r 2$ & 13 & 14 & 15 & & & \\
\hline$A^{\prime}$ & 8 & 6 & 2 & 9 & 7 & 4 & & $12.44 \%$ \\
\hline$B^{\prime}$ & 14 & 7 & 2 & 8 & 11 & 4 & & $16.33 \%$ \\
\hline$c^{\prime}$ & 2 & 1 & 1 & 5 & 1 & 4 & & $3.88 \%$ \\
\hline$\triangle B C^{\prime}$ & 13 & 10 & 2 & 14 & 10 & 4 & 2000 I & $19.05 \%$ \\
\hline$A B^{\prime}$ & 7 & 11 & 2 & 23 & 2 & 4 & $200 t 1$ & $2090 \%$ \\
\hline$B C^{\prime}$ & 9 & 6 & 6 & 4 & 4 & 4 & & $12.15 \%$ \\
\hline $\mathrm{CA}^{\prime}$ & 10 & 10 & 13 & 8 & 8 & 4 & & $19.93 \%$ \\
\hline "I," & 0 & 1 & 0 & 0 & 0 & 4 & & $0.48 \%$ \\
\hline$A^{\prime}$ & 0 & 0 & 0 & 0 & 0 & 7 & & $000 \%$ \\
\hline$B^{\prime}$ & 2 & 1 & 10 & 0 & 0 & 7 & & $5.05 \%$ \\
\hline$C^{\prime}$ & 0 & 0 & 0 & 0 & 0 & 7 & & $000 \%$ \\
\hline$A B C^{\prime}$ & 1 & 1 & 0 & 0 & 0 & 7 & & $0.77 \%$ \\
\hline$A B^{\prime}$ & 2 & 3 & 2 & 2 & 0 & 7 & 20001 & $4.37 \%$ \\
\hline$B C^{\prime}$ & 0 & 0 & 0 & 0 & 0 & 7 & & $0.00 \%$ \\
\hline$C A^{\prime}$ & 0 & 0 & 0 & 0 & 0 & 7 & & $0.00 \%$ \\
\hline "1," & 0 & 0 & 0 & 0 & 0 & 7 & & $0.00 \%$ \\
\hline $8^{\prime}$ & 1 & 0 & 0 & 0 & 0 & 10 & & $0.38 \%$ \\
\hline$A B^{\prime}$ & 0 & $i$ & 1 & 0 & 0 & 10 & Zoeo II & $0.77 \%$ \\
\hline$A B C^{\prime}$ & 0 & 0 & 0 & 1 & 0 & 10 & & $0.388 \%$ \\
\hline$\theta^{\prime}$ & 1 & 0 & $\overline{0}$ & 0 & 0 & 15 & & $0.38 \%$ \\
\hline$A B^{\prime}$ & 0 & 0 & 1 & 0 & 0 & 15 & 2000 III & $0.39 \%$ \\
\hline
\end{tabular}




\section{ALIMENTACION DE LARVAS}

En la Fig. 5 se graficó el logaritmo de las pendientes promedio (Ln m) de sobrevivencia de las larvas en todos los tratamientos versus los días en que se hicieron los controles. Con ambos parámetros se calcularon las pendientes m que expresan una estimación de la sobrevivencia larval con respecto al tiempo (Tabla 10). En éste experimento los tratamientos en relación a la sobrevivencia de las larvas fueron significativos al $0.05 \%[F=0.05(6,40)=2.34 ; \mathrm{Fs}=4.38]$ (Tabla 11).

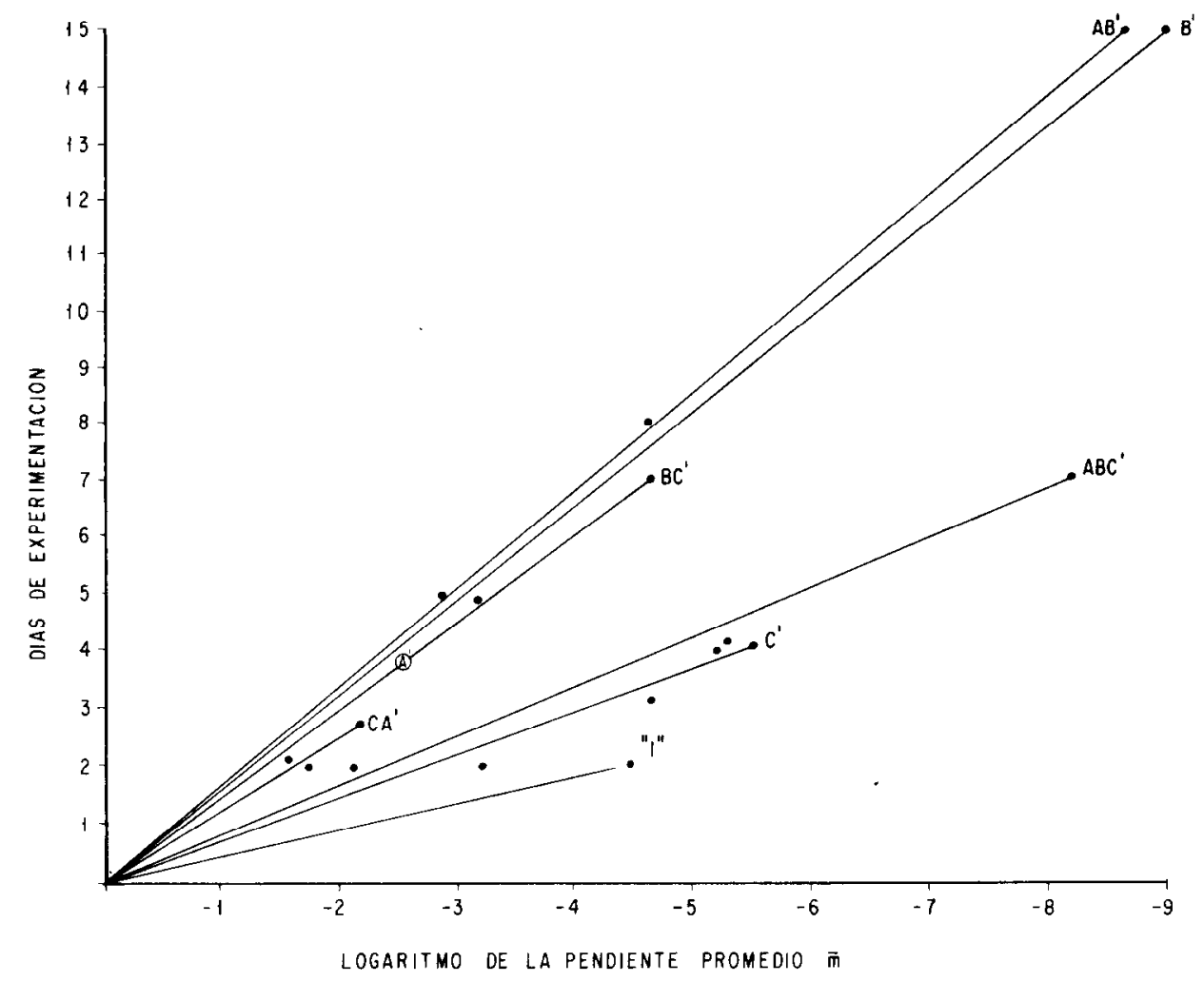

Fig. 5.- Contrastación de las pendientes promedio de sobrevivencia para cada combinación alimenticia del experimento II versus días de control.

Con el resultado indicando diferencias significativas en las sobrevivencias larvales promedio, se aplicó el análisis de comparación Múltiple "A Posteriori" (Sokal y Rohlf, op. cit.) que detectó una significancia para el tratamiento $\mathrm{C}^{\prime}$ con respecto a $A B^{\prime}, B^{\prime}, A^{\prime} C^{\prime}$ y $B^{\prime} C^{\prime}$. Es decir, que los últimos tratamientos marcan jerárquicamente de mayor a menor (Tabla 12) un efecto sobre la sobrevivencia, siendo el primero $\left(\mathrm{AB}^{\prime}\right)$ el mejor tratamiento alimenticio (yema de huevo, $B$. pli- 


\section{Denise Re-Buckle}

catilis) en este experimento. Sin embargo, todos los tratamientos que tienen como componente al Rotífero son también buenas combinaciones (Tabla 12).

Tabla 10. Valores de las pendientes $(\mathrm{m})$ y sus promedios $(\mathrm{m})$ de cada tratamiento del experimento II, calculados en base a los datos de sobrevivencia en el tiempo.

\begin{tabular}{|c|c|c|c|c|c|c|c|}
\hline ALIMENTO & $A^{\prime}$ & $B^{\prime}$ & $c^{\prime}$ & $A B C^{\prime}$ & $A B^{\prime}$ & $B C^{\prime}$ & $\mathrm{CA}^{\prime}$ \\
\hline \multirow[t]{14}{*}{ m (pendientes) } & 1.02 & 0.89 & 1.61 & 0.80 & 0.78 & 1.06 & 0.80 \\
\hline & & 0.56 & 1.06 & 0.92 & 0.63 & 0.498 & \\
\hline & & 0.66 & 0.70 & 0.76 & 0.53 & & \\
\hline & & 0.35 & & 0.56 & 0.43 & & \\
\hline & & 0.90 & & 1.00 & 0.11 & & \\
\hline & & 0.36 & & 0.35 & 0.53 & & \\
\hline & & 0.53 & & 0.093 & 0.37 & & \\
\hline & & 0.37 & & 0.74 & 0.41 & & \\
\hline & & 0.47 & & 0.50 & 0.29 & & \\
\hline & & 0.55 & & 0.35 & 0.34 & & \\
\hline & & 0.32 & & 0.20 & 0.48 & & \\
\hline & & 0.29 & & 0.094 & 0.38 & & \\
\hline & & 0.10 & & & 0.23 & & \\
\hline & & 0.48 & & & & & \\
\hline$n$ & 1 & 14 & 3 & 12 & 13 & 2 & 1 \\
\hline $\bar{m}$ (promedio) & 1.02 & 0.488 & 1.12 & 0.530 & 0.4238 & 1.186 & 0.80 \\
\hline$s^{2}$ & - & 0.049 & 0.2079 & 0.99 & 0.0299 & 0.569 & - \\
\hline
\end{tabular}

Tabla 11. Análisis de Varianza de comparación de las pendientes promedio de sobrevivencia de todos los tratamientos alimenticios del experimento II.

\begin{tabular}{|c|c|c|c|c|c|}
\hline \multirow[b]{2}{*}{ Fuente de varioción } & \multicolumn{2}{|c|}{ ANALISIS } & VARIANZA & \multicolumn{2}{|c|}{ EXPERIMENTO II } \\
\hline & & g. 1 . & s. s. & m. s. & f. s. \\
\hline SS entre grupos & & 6 & 1.641 & 0.2735 & 4.383 \\
\hline SS intro grupos & & 40 & 2. 496 & 0.0624 & \\
\hline 10101 & & 46 & 4. 137 & & \\
\hline & $F$ & 0.05 & $(6,40)$ & 2.34 & $83^{*}$ \\
\hline & $F$ & 0.01 & $(6,40)$ & 3.29 & $83^{* *}$ \\
\hline & $F$ & 0.001 & $(6,40)$ & 4.73 & 83 \\
\hline
\end{tabular}


Tabla 12. Prueba de comparación Múltiple "A Posteriori" de las pendientes promedio de sobrevivencia larval para todos los tratamientos alimenticios del experimento II.

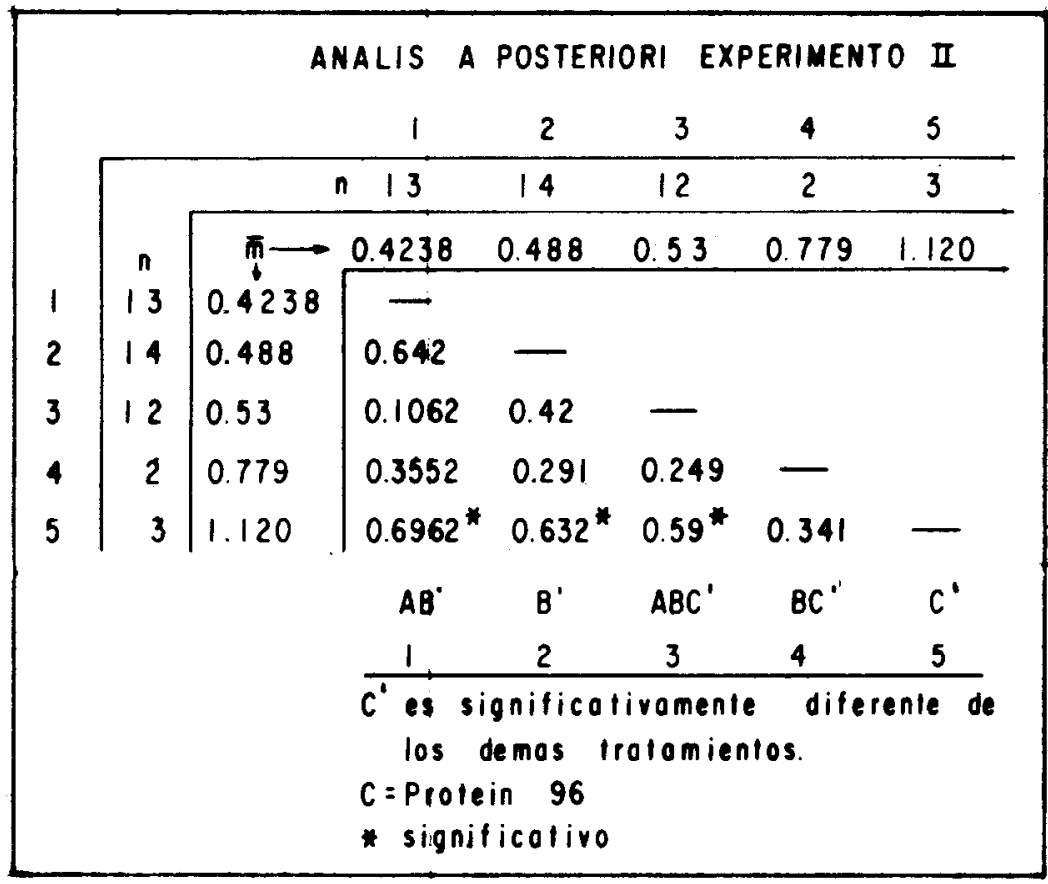

\section{DISCUSION}

El sistema de cultivo diseñado en la investigación de una biotecnia para las larvas de $C$. antennarius desde el punto de vista de la Aquacultura, se aleja de aquellos donde las metas son describir cada uno de los estadíos larvales de las especies estudiadas para lo cual se recurre a densidades muy bajas de larvas (Roesijadi 1976; Poole, 1966). En el primer experimento de esta investigación se utilizaron 408,000 y en el segundo 200,000 larvas. Pese a la gran cantidad de animales que entraron a los experimentos, estos aún se encuentran a un nivel exploratorio y no constituye la biotecnia definitiva, debido a que es necesario investigar otras relaciones igualmente importantes como son, el efecto de la variación de la temperatura y la salinidad en la sobrevivencia de los diferentes estadíos larvales. El sistema de cultivo ideado en esta investigación puede transformarse para esos objetivos.

El diseño experimental factorial (Snedecor y Cochran, 1970) utilizado, implicó un número elevado de réplicas (Snedecor y Cochran, 1978) que garantizaron una mayor confiabilidad en los resultados. Sin embargo, la calidad y procedencia del material biológico fue un factor muy importante en la realización de los expe- 
rimentos. Fue claramente evidente (en el segundo experimento) que los progenitores adaptados a las condiciones de laboratorio, desde el apareamiento hasta la eclosión de las larvas, generaban individuos con mayor probabilidad de sobrevivencia durante los primeros estadíos larvales como se reflejó en los tratamientos B 'y $\mathrm{AB}^{\prime}$.

La subrevivencia indicada para utrus cultivos de Cancer spp., en la primera etapa de Pre-Zoea a Zoea I es de un 30\% (Poole, 1966). Trask, (1970) refiere una sobrevivencia de un $50 \%$ en el estadío de Zoea V cuando sobreviene la metamorfosis al estadío de Megalopa y también sugiere que la alta mortalidad puede ser debido a las dificultades que tiene la larva para salir del exoesqueleto. Es Callinectes sapidus la sobrevivencia de las larzas Zoeas en su medio natural, no supera a $5 \times 10^{-5}$ o/o (Millikin, 1978). Fisher y Wickham, (1976), suponen que la presencia de microbios epibiónticos son los responsables de la mortalidad larval en la naturaleza. Nilson et al. (1975) indican que la mortalidad en el laboratorio, es causada por enfermedades de tipo bacteriano que impiden el intercambio gaseoso a través de la membrana del huevo y en la etapa larval, en las membranas de las branquias; o bien por que hongos de formas filamentosas aprisionan los apéndices de las larvas. Durante la examinación de las muestras, algunas larvas estaban infectadas con hongos filamentosos adheridos a estructuras del exoesqueleto. Los hongos no constituyeron un factor de regulación en la sobrevivencia de estos experimentos.

En el experimento 1 las larvas se alimentaron con comida de gato (Cat Chow) Skelectonema costatum y yema de huevo (Tabla 3) a una concentración de $0.007 \mathrm{~g} / \mathrm{l}$. Los análisis estadísticos revelaron que la combinación de yema de huevo y microalgas era favorable para la sobrevivencia de las larvas del estadío Zoea I (Tabla 7). Pese a la alta mortalidad de larvas que hubo en este ensayo, la sobrevivencia controlada al tercer día entre los estadíos de Pre-Zoea a Zoea I fue mas alta que la indicada por Poole op. cit. ( $\mathrm{x}=46 \mathrm{o} / \mathrm{o}, \mathrm{DS}-13)$. Al quinto día la sobrevivencia de todos los tratamientos fue de un promedio de $5 \%$ DS = 6 (Tabla 4). Se estima que la alta mortalidad detectada en el tercero y quinto día de control, se debió en gran medida a la calidad del alimento que pudo repercutir en las larvas que se enfrentan a la ecdycis y a la alta temperatura del agua $\left(23^{\circ} \mathrm{C}\right.$ ). Sin embargo, cabe destacar que en el quinto día de control se comprobó en el tratamiento en que se combinó Skeletonema costatum con yema de huevo (Tabla 4), una sobrevivencia de Zoea I de un $\mathrm{x}=19.20 \%$. En el control antes referido, los alimentos indicados, adicionados en forma pura a las larvas, solo permitieron en el primero una sobrevivencia de $\mathrm{x}=0.19 \%$ o en el segundo un $\mathrm{x}=3.11 \mathrm{o} / \mathrm{o}(\mathrm{Ta}$ bla 4 ).

El efecto de la administración de la vitamina $\mathrm{C}$ al alimento, no se pudo evaluar por que las larvas no avanzaron en el desarrollo al estadío de Zoea II.

En vista de los resultados que se habían tenido, los alimentos se cambiaron 
conservando la yema de huevo como un ingrediente e incluyendo Protein 96 $(0.001 \mathrm{~g} / 1)$ y el Rotífero Bracbionus plicatilis (Kittaka, 1975) (Tabla 8). Estas modificaciones hicieron posible incrementar el tiempo de duración del experimento II. En el séptimo día de control los tratamientos de Rotíferos puros y combinados (estadísticamente significativos) (Tabla 12) no aumentaron la tasa de sobrevivencia del estadío Zoea I obtenido en el experimento I. Sin embargo, la adición de $B$. plicatilis extendió el desarrollo larval hasta el estadío de Zoea III con una sobrevivencia del $0.38 \%$ (Tabla 9 ).

Se observó que el volumen del muestreador calculado en base al número inicial de larvas que se introducían en los acuarios, perdía en el transcurso del ensayo la sensibilidad requerida para detectar el númcro rcal de larvas. Consecuentemente se estima necesario que para este tipo de cultivo, el muestreador se ajuste volumétricamente en base a la curva de mortalidad.

De este estudio se desprende que el cultivo de Cancer antennarius depara grandes dificultades en la consecución de una biotecnia compatible con la $\Lambda$ quacultura. El cultivo de larvas se hizo con las condiciones ambientales de verano (experimento I) y de inviemo (experimento II). Los resultados indican que los cultivos se ven favorecidos cuando los progenitores se adaptan a las condiciones de laboratorio (especialmente de invierno) donde los procesos de reproducción se expresan en una mayor sobrevivencia larval si se incluye (durante el estadío de Prezoea a Zoea I) una alimentación de microalgas y yema de huevo y en los estadíos de Zoea II y III, alimentos especialmente de origen animal.

Es posible que para el logro de una biotecnia efectiva en los otros estadíos larvales de $C$. antennarius sea necesario identificar nuevos alimentos.

\section{AGRADECIMIENTOS}

Los autores expresan su agradecimiento al Dr. Robert Ogden por sus atinadas indicaciones en el análisis estadístico.

Extendemos nuestra gratitud a la Secretaría de Educación Pública (S.E.P.) por el apoyo económico que brindó a esta investigación a través del Instituto de Investigaciones Oceanológicas (I.I.O.) (U.A.B.C.).

\section{LITERATURA CITADA}

ANDERSON, W.R. y R. F. Ford, 1976. Early development, growth and survival of the yellow crab Cancer antbonyi (Rathbun) (DECAPODA BRACHYURA) in the Laboratory. Aquaculture, 7:267-279.

BAILEY, N.T.J., 1959. Statistical methods in biology. The English Universities Press LTD, London. 
BUCHANAN, D.V. y R.E. Milleman, 1969. The prezoeal stage of Dungeness crab, Cancer magister Dana. Biol. Bull. 137 (5): 250-255.

Biochem. Physiol.). Vol. 44-A: 821_828.

BENNETT, D.B., 1973. The Effect of limb loss and regeneration on the growth of the edible crab, Cancer pagurus L; J. Exp. Mar. Biol. Ecol. Vol. 13: 45-53.

BUCHANAN, D. V. y R. E. Milleman, 1969. The prezoeal stage of Dungeness crab, Cancer pagurus L; J. Exp. Mar. Biol. Ecol. Vol. 13: 45-53.

BUCKLE, F., Ch. Guisado, E. Tarifeño, A. Zuleta, L. Cordova, C. Serrano y R. Maldonado, 1976. Estudios biológicos del erizo Loxechinus albus (Molina) (Echinoidea, Echinodermata). Biol. Pesq. Chile. No. 8:31-64.

COCHRAN, W. G. y M. G. Cox, 1976. Diseños experimentales. Edit. Trillas, Méx.

COCHRAN. W. G., 1978. Técnicas de muestreo. C.E.C.S.A. cap. No. 4: 105 - 112. Fisher, W. S. and D.E. Wickham, 1976. Mortalities and epibiotic fouling of eggs from wild populations of the Dungeness crab, Cancer magister. Fish. Bull. (U.S.) 74: 201-207.

FISHER, W. S. y R. T. Nelson, 1977. Therapeutic treatment for epibiotic fouling on Dungeness crab Cancer magister larvae reared in the Laboratory. J. Fish. Res. Board Can. 34: 432-436.

HARTNOLL, R. G., 1974. Variation in growth pattern between some secondary sexual characters in crabs (Decapoda Brachyura). Crustaceana, 27 (2): 129136.

JORGENSEN, B., 1954. Quantitativa aspects of filter feeding in Invertebrates. Biol. Review, 30: 391-453.

KITTAKA. J., 1975. Food and growth of Penaid Shrimp Proceedings of the First International Conference on Aquaculture Nutrition. October 1975.

MILLIKIN, M. R., 1978. Blue crab larval culture. Methods and Management Marine Fisheries Review, NOAA. Vol. 40 No. 11. 1978: $10-17$.

MIR, R.D., 1961. The external morphology of the first zoeal stages of the crabs, Cancer magister, Dana, Cancer antennarius, Stimpson, and Cancer anthonyi Rathbun. California Fish and Game, 47(I): 103 - 111. 
NILSON, E. H. S. Fisher, and R. A. Shleser, 1975. Filamentous infestations observed on eggs and larvae of cultured crustaceans. Proc. 6 th. World Mariculture Soc. 6: $367-375$.

PARSONS, T. R., K. Stephens y J. D. H. Strickland. 1961. On the chemical composition of eleven species of marine phitoplankters. Fish. Res. Bd. Canadá, $18(6)$ : 1001 - 1015.

POOLE, R. L., 1966. A description fo laboratory reared zoeae of Cancer magister (Dana) and megalopae taken under natural conditions (Decapoda, Brachyura). Crustaceana, 11: 83-97.

RATHBUN., M. J. 1930. The cancroid crabs of America. Bull U.S. Natl. Mus. 152: 1 - 609 .

REED, P.H., 1969. Culture methods and effects of temperature and salinity on survival and growth of Dungeness crab Cancer magister larvae in the laboratory. J. Fish. Res. Board Can., 26: 389 - 397.

ROESIJADI, G., 1976. Descriptions of the Prezoeae of Cancer magister (Dana) and Cancer productus (Randall) and the larval stages of Cancer antennarius (Stimpson) (Decapoda Brachyura). Crustaceana, 31 (3): 275 - 295.

ROHLF, F. J., y R. R. Sokal, 1969. Statistical Tables. Freeman. Edit. : 168 198.

SASTRY. A. N., 1977a. The larval development of the Rock Crab, Cancer irroratus (Say, 1817) under laboratory conditions. (Decapoda, Brachyura) Crustaceana, $32(2): 155-168$.

SASTRY, A.N., 1977b. The larval development of the Jonah Crab, Cancer borealis (Stimpson, 1959), under laboratory conditions (Decapoda Brachyura). Crustaceana, 32 (3): 290 - 303.

SCHEFLER, W. C., 1969. Statistics for the biological sciences. addison Wesley Publishing Company: 104 - 113.

SNEDECOR G.W. y W. G. Cochran, 1970. Statistical Methods. The IOWA State University Press, Ames, IOWA, U.S.A.

SNEDECOR G. W. y W. G. Cochran, 1978. Métodos Estadísticos C.E.C.S.A. Capítulo 14: 513 - 520 .

SOKAL, R. R. y F. J. Rohlf, 1969. Biometry, W. H. Freeman and Company Edit. : $146-205$. 
THEILACKER, G. H. y M. F. McMaster, 1971. Mass culture of the rotifer Brachionus plicatilis and its evaluations as a food for larval anchovies. International Journal on Life in Oceans and Coastal Waters, Vol. 10, No. 2: $183-188$.

TRASK, T., 1969. A description of laboratory-reared larvae of Cancer products Randall (Decapoda, Brachyura) and a comparison to larvae of Cancer magister (Dana). Crustaceana, 18 (2) : 133 - 146.

VARGO, S. L. y A. N. Sastry, 1977. Acute temperature and low dissolved oxygen tolerance of Brachyuran Cancer irroratus larvae. Marine Biology, 40: 165 171 . 